\title{
'Broadcasting Indian TV Serials In Bangladesh: The Beginning of the Social Change': A Study on Present Situation of Bangladesh
}

\author{
${ }^{1}$ Dilafroze Khanam , ${ }^{2}$ Mohammad Mufajjal Sarwar \& \\ ${ }^{3}$ Tareq Mahamud Abir \\ ${ }^{I}$ Department of Sociology, University of Barisal, Barisal, Bangladesh \\ ${ }^{2}$ Department of English, Government Women's College, Barisal, Bangladesh \\ ${ }^{3}$ Department of Sociology, University of Barisal, Barisal, Bangladesh
}

\begin{abstract}
This article aims at portraying the present situation of Indian TV channels and Indian TV programs in our country identifying the major weak points of Bangladeshi channels according to the respondents view. Moreover, this article also tries to show viewers addiction level to those programs especially to the Indian TV serials and the reasons behind the high popularity of those serials among all ages, sexes and education levels. In addition, this paper argues that in future our unlimited interest in Indian serials will affect our norms, values, socialization process, social institutions and especially our future generation.
\end{abstract}

Keywords: Indian TV Serials, Social Change, Indian TV channels, Bangladeshi channels, socialization, social institutions

\section{Introduction}

Today television has become an inseparable part of our life. This statement has become much true after the accessibility of cable TV in all the cities and towns of our country. Nowadays, with the access to cable TV the entire population of our country can be easily divided into two segments: those who watch Indian channels and those who don't. The female populations of our country prefer Indian TV serials rather than any other programs telecasted by Indian channels. Female of various categories like pre- teens, teens, students from renowned institutions, working women, homemakers, old age women, almost women in every sector are the main viewers of Indian serials. Moreover, not only women but also the male members of the family and children are the viewers of Indian serials. Undoubtedly it can be said that such kind of involvement of female population must affect our future generation, either negatively or positively.

To portray the present situation of Indian channels and programs especially Indian serials, the article is divided into five sections. Section one provides an account of historical development of Indian TV channels and its consumption in Bangladesh. Section two presents a brief analysis of present situation of Indian TV channels and Indian TV serials in Bangladesh. Section three represents the impact of Indian TV serials on our future generation and the present situation of Bangladeshi channels are analyzed in the section four. In the fifth section a theoretical relations have been tried to relate to the topic.

\section{Concept Of Indian TV Serials/ Indian Daily Soap}

As to Wikipedia -" Daily soap operas are the genre of television program based on episodic work of dramatic fiction".

Why the serials are called soaps? The history is very interesting. Shoma Munshi, professor of anthropology at the American University of Kuwait (AUK) explains in her writings, "Soap operas are in fact referred to as 'Soaps' because their origins lie in the 1950s radio dramas in the US that were broad casted during the day, when women were mainly at home doing household chores. These radio dramas were sponsored by companies such as Proctor \& Gamble, Colgate- Palmolive and Lever Brothers who were soap manufacturers, hence the name, which stuck" (Munshi 2009).

These daily soaps portray stories to which people can relate their lives with. In addition, soap operas all around the world are women -centric and have women viewers as target audience.

In this article, the term 'Indian TV Serials' or 'Indian Daily Soap' means soap operas that are written, produced, filmed in India, with characters played by Indians, with episodes broadcasted on Indian television channels.

Indian daily soaps are not only broadcasted in India but also in other countries. Wikipedia's information is "Except India, UK, USA, Europe, Asia and Australia Indian serials are telecasted. The most common languages in which Indian serials are made in are: Hindi, Punjabi, Marathi, Gujarati, Bengali, Tamil, Kannada, Telugu, and Malayalam etc". 


\section{The History of Indian TV Channels and Its Consumption in Bangladesh}

To describe the emergence of Indian TV channels in Bangladesh, at first we have to come across the beginning of Satellite Television (STV) in Bangladesh.

STV appeared in Dhaka city for the first time in 1991 and in 1992 government legalized the Television Receive Only Dish (TVRO) system but the installation fee of TVRO was so high in the first stage. However, the scenery was changed after 1993. At that time the cable operators wired up centers in different parts of the Dhaka city to make the cable connection available to all. Goonesekera described the situation which is cited by Huda-" Although CNN pioneered the direct transnational broadcasting in the decade of eighty the general viewers of Bangladesh eagerly viewed the programs of Doordorshan by using the boaster antenna. These attempts of the viewers ended with the advent of Indian channels like Zee TV, Zee Cinema, Sony etc" (Goonesekera 1998:7 cited by Huda 2007).

At present more than ninety TV channels are broadcasted in Bangladesh, out of which twenty three are Bangladeshi, including the government owned terrestrial channel Bangladesh Television (BTV). The rest are foreign language channels, the majority of which are Indian market based. Among these more than forty are purely Indian channels in different languages including Hindi and Bangla.

\section{The Objectives}

The broad objective of the study is to portray the present situation of Indian TV channels in Bangladesh. In specific terms, the objectives of the study are as follows:

1. To examine the popularity of Indian TV channels in Bangladesh.

2. To identify the popular Indian TV programs in Bangladesh.

3. To portray the present situation of addiction to Indian TV serials in Bangladesh.

4. To analyze the impact of Indian TV serials on the future generation of Bangladesh.

5. To identify the weak points of Bangladeshi TV channels to attract the native viewers and the solution of the weakness.

\section{Methodology of the Study}

Based on the research objectives, this study combines both Qualitative and Quantitative methods which include the followings:

Survey is the main technique that has been used throughout the research in response to the Quantitative method. Data have been collected from four districts namely Dhaka, Kishorgonj, Barisal and Jhalakati to make the findings representative. However, survey areas and respondents are selected purposively. In this research data have been collected from 80 respondents who are selected purposively, among them 20 are male and 60 are female respondents. In addition, 45 children are surveyed to collect data about the impact of Indian TV serials on them who are two to ten years old. Secondly, a psychiatrist and two play directors are interviewed to get special information. Thirdly, four case studies have conducted.

As there exists no former research works or articles on the topics, researcher faced many problems in literature review, data presentation and making comparison between the past and present situation.

\section{Findings of the Study and Discussion}

Nowadays, our print media and electronic media often present different news, opinions and reports related to Indian serials. For example, 6 August, 2010 in 'THE STAR', a supplementary of 'The Daily Star', a woman seeks suggestion in the letter section of the magazine in this way-"I am a housewife who loves Hindi serials. I watch almost every show on Star Plus and Zee TV. Recently, my family has been complaining that I don't have enough time for them because I am always in front of the TV. I have neglecting my house work, my children and my friends and I did not even notice until it was pointed out to me. I think the serials have become somewhat of an addiction but I am hooked. I cannot sleep well at night unless I am up to date on my shows. Please tell me how I can get out over this" (The Star 2010).

Is the situation so adverse? This research wants to reveal the present situation of our country.

\section{Demographic characteristics of the respondents}

Table 1: Demographic characteristics of the respondents

\begin{tabular}{|c|c|c|c|c|}
\hline \multirow{2}{*}{ Sex } & Male & Female & \multicolumn{2}{|c}{} \\
\cline { 2 - 3 } Age (In year) & 20 & 60 & $\mathbf{2 0 - 3 0}$ & $\mathbf{3 0}+$ \\
\cline { 2 - 4 } & $\mathbf{0 2 - 1 0}$ & $\mathbf{1 0 - 2 0}$ & 40 & 20 \\
\hline \multirow{2}{*}{ Profession } & 45 & 20 & Homemaker & 30 \\
\cline { 2 - 4 } & Student & 15 & Employee & 30 \\
\hline
\end{tabular}


'Broadcasting Indian TV Serials In Bangladesh: The Beginning of the Social Change': A Study ...

The average time of $\mathrm{TV}$ watching:

The average time of watching TV of the respondents is four hours.

The most popular Indian TV channels in Bangladesh:

The respondents of this study listed 39 foreign channels which they watch frequently. Most of the channels are Indian. The most popular seven Indian channels are shown in the graph below:

Graph 1: Showing the popular Indian TV channels in Bangladesh

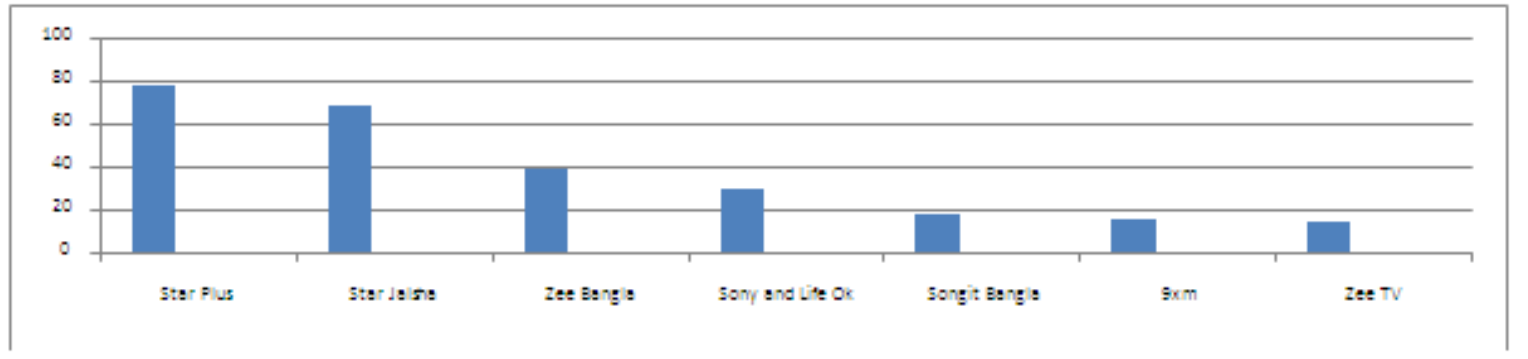

Findings of the study show that Star Plus is the mostly watched channel. This is because Star Plus is one of the oldest channels and people are acquainted with it for a long time. In addition, Star Plus broadcasts a large number of Hindi serials all day long.

A survey conducted by 'Centre for Communication and Research' in 1994 portrayed the popularity of Hindi channels in Bangladesh where Zee TV, STAR Plus were ranked as very popular channels. The survey showed that in Bangladesh 41\% city viewers revealed their passion for Zee TV, 21\% were identified as the viewers of Channel 5, 11\% adored STAR Plus and 7\% watched Prime Sports regularly in Dhaka city (Rahaman 1994: 11, cited by Huda 2007).

Going through the study it can be said that popularity of Indian channels is increasing day by day not only in the Dhaka city but also all over Bangladesh due to the availability of TVRO support and the least consumption rate. On the contrary, not a single Bangladeshi TV channel is shown in India though Bangladeshi channels are already available on major cable networks in United States, Europe and the Middle East.

\section{The most popular Indian TV programs}

A lot of programs are shown in Indian TV channels daily. Among these programs the respondents of the study chose the followings as their favorite:

\section{Graph 2: Bar Graph showing the popular Indian TV programs in Bangladesh}

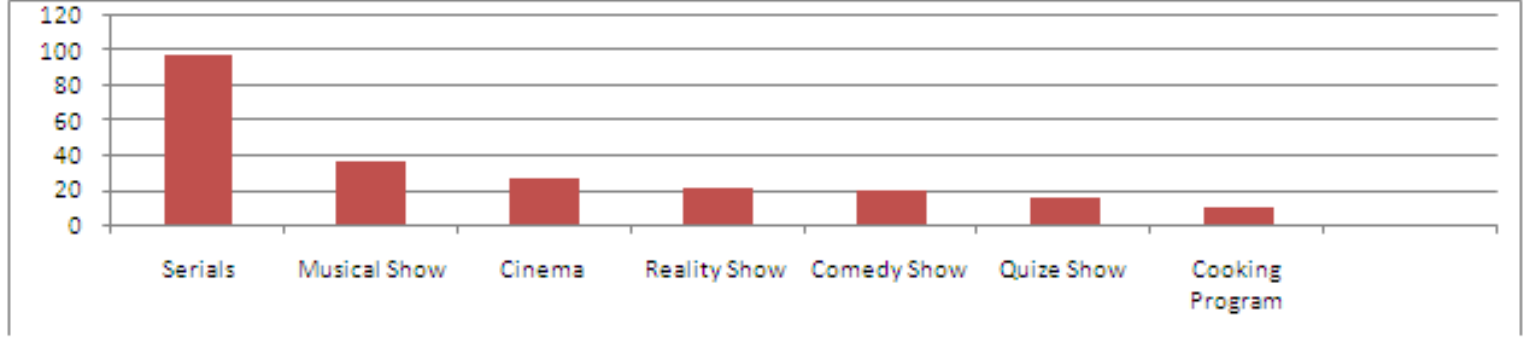

The graph shows that among all the programs broadcasted by Indian channels, serials are most popular among the respondents of different ages, sexes, educational qualifications etc. Nowadays, a large number of people of our country watch Indian serials and in coming time it would be hardly possible to find a family where at least a single member is not the viewer of Indian serials.

\section{The most popular Indian TV serials in Bangladesh}

Indian TV serials are not only broadcasted in different countries but also so much popular in those countries as Wikipedia says- "Indian soap opera have gained popularity abroad, across South Asia and beyond into Afghanistan, Southeast Asia, and among the Indian Diaspora elsewhere. A number of Hindi soap operas have also been dubbed into Mandarin and gained popularity in China" (Wikipedia 2013).

The popularity of Indian TV serials are increasing day by day around the world. In this study, the respondents listed 68 Indian TV serials they watch regularly. Among them ten are most popular such as- Iss 
pyaar kya naam doon, Maa, Tapur tupur, Diya aur baati hum, Saathiya, Valobasa.com, Ak hajaro me meri bahna, Esti kutum, Saath nibhana saathiya, Keya patar nouko.

\section{Main Viewers of Indian TV serials}

All the Indian TV serials are women-centric and key characters are female. It's a strategy to increase the number of viewers especially women viewers. Shoma Munshi's writings also support such statements. She wrote- "The very genre of soap operas is women-centric. This is the case not just in India, but anywhere in the world. The soaps' characteristic address is to women viewers" (Munshi 2009).

In Bangladesh main viewers of Indian TV serials are women. All the respondents of the study told that women especially homemakers, who are not engaged in productive activities are the main viewers of such kind of soaps. As women are the key viewers of Indian TV serials, it will affect their family life and also the future generation.

\section{The Themes of Indian TV serials}

The majority of Indian television shows are based on the Family and Marriage theme. The titles of most of the serials support above statement i.e. Maa (Mother), Sansar sukher hoy Romonir Gune (A wife makes a family happy), Bodhu Kon Alo Laglo Chokhe (Oh dear, what enthralls thy eyes), Sasural genda phool (InLaws house is like a Marigold), Saat Pake Bandha (Bondage of seven circles) etc. The findings of the study show that the themes of present Indian TV shows are the followings:

\section{Graph 3: Showing the major themes of Indian TV serials}

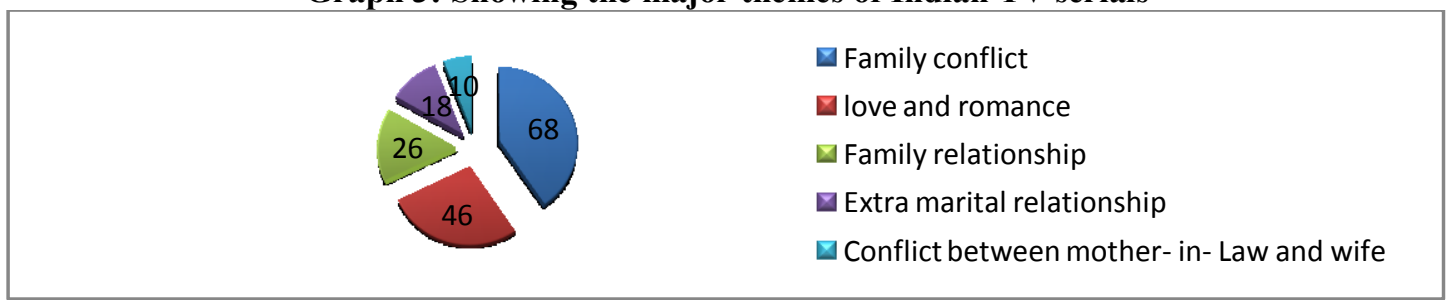

Most of the serials share common themes like family relationship, romance, humor, conflicts, social problems, Hindu mythology etc which attracts women most. Why women are the main viewers of these themes? A play director said:

Most of the serials show family conflict of different patterns and women like it perhaps they are facing the same reality or they are interested in it naturally.

\section{Measuring addiction to Indian TV serials}

One of the respondents told that 'Serials are like nicotine; once you watch it, you get addicted'. Is it true? To measure the addiction level, this study asked the respondents whether they watch each episode of the serials more than one times or not. The result is shown by a pie chart bellow:

\section{Graph 4: Showing the addiction to Indian TV serials}

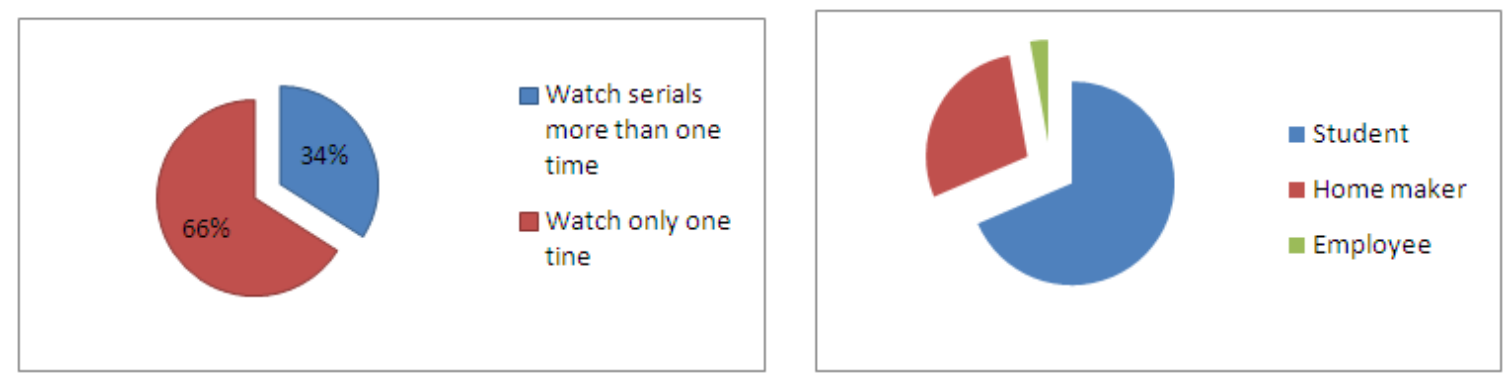

At present each Indian TV serial is shown two or three times a day. Due to high publicity people are bound to watch them. The graph shows that, $34 \%$ respondents watch their favorite TV serials more than one time a day. The important information is that those who watch serials more than one time daily, are mostly students of different classes. Among those 34 percent respondents 23 percent are students, 10 percent homemakers and 1 percent employee. It is an alarming fact for our future generation. Moreover, not only the school and college going children but also those who have not started to go to school yet, are the viewers of serials. 
A student of 18 year's old says that "Watching serials are like one kind of addiction, I wish if I could watch all the serials!". Most of the viewers are closely attached to their favorite serials. Anwar describes the situation:

"Attachment to the favorite serials is going in such level that many people admit to crying when a tragedy occurs in the household of the predominant character" (Anwar, 2005).

\section{Case Study-01}

Name: Md. Mosaddek Reza, age: 45, educational qualification: graduate, profession: business lives in Segunbagicha, Dhaka. He watches Indian serials regularly. He likes Indian serials because he thinks they're family oriented. The stories of serials touch him intensely. He told that when his favorite characters fall in tragedy or when a family tragedy is shown in the serials he can not control his emotion and he cries like a child. However, the other members of his family don't watch serials. His wife and son always watch channels which don't telecast serials.

\section{How the Respondents Manage Time to Watch the Serials}

Most of the Indian TV shows are thirty minutes long. All the respondents of the study watch more than five TV shows daily. How do they manage time to watch serials after passing a very busy day for each of them? Their answers are presented in the following graph:

\section{Graph 5: Ways of creating scope and time to watch serials}

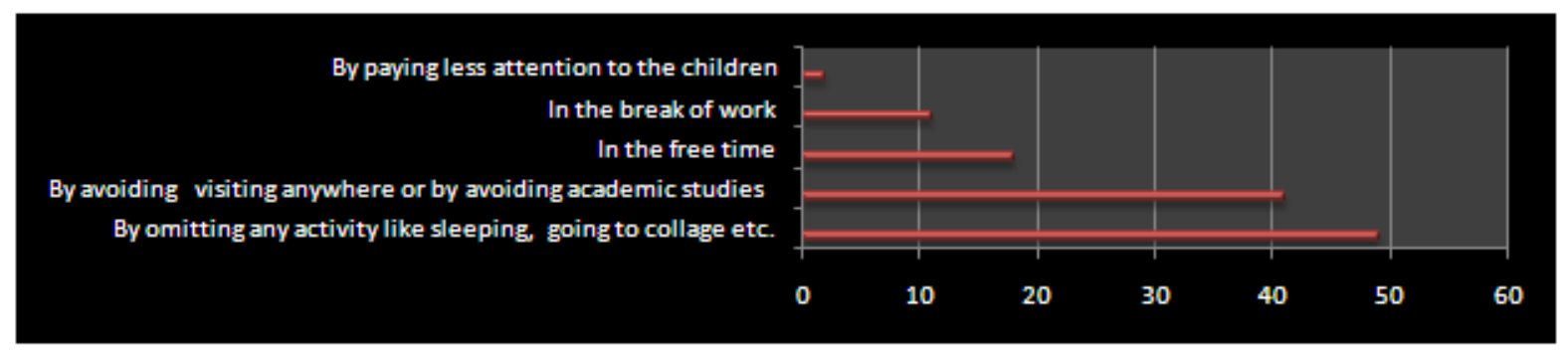

All the ways of creating scope and time to see the serials are not simple. However, reluctance to visiting anywhere, not to perform academic duties perfectly, paying less attention to family and children all these ways are alarming.

\section{Case Study-02}

Name: Munni Begum, age: 32, educational qualification: S.S.C. Occupation: Homemaker lives in Jhalakati. She watches television six hours daily and watches eight to ten serials regularly. She manages time to watch serials by omitting any activity from her daily schedule and by paying less attention to her son who is a boy of class six. Her husband lives abroad and she and her son are the present family members. They live in a small room where in one side she watches TV and on the other side her son studies. In the middle of the room she draws a curtain to avoid disturbing him. She said that she pays more attention to the serials than teaching her son.

\section{Reasons behind Watching Indian TV Shows}

"When an elegant woman, wearing a dazzling sari and classy jewelry, is being telecasted on a show, the audience certainly gets anchored to their television sets. For a moment they get swayed by the beauty of the woman" (Ghale \& Karna, 2009). Nowadays gorgeous presentation of women characters is one of the strategies adopted by the television industries in India to increase the number of viewers.

The directors follow every strategy to catch viewers. For example, clothes, jewelries, make-up, hair style, fashion, location, other household setting, stories etc. are used to increase viewers as Ghale and Karna said:

To make each serial exclusive the director chooses unique clothing and accessories. Ostensible daily soap operas are made to deliver messages regarding culture, family relations, struggles of life and mythology through stories, but instead of the story, the audience is fascinated by the dresses, actors and the jewelries" (Ghale \& Karna, 2009).

The findings of the study show that not only the story but also other accessories hooked the viewers to the Indian serials. 


\section{Graph 6: Showing reasons for watching Indian serials}

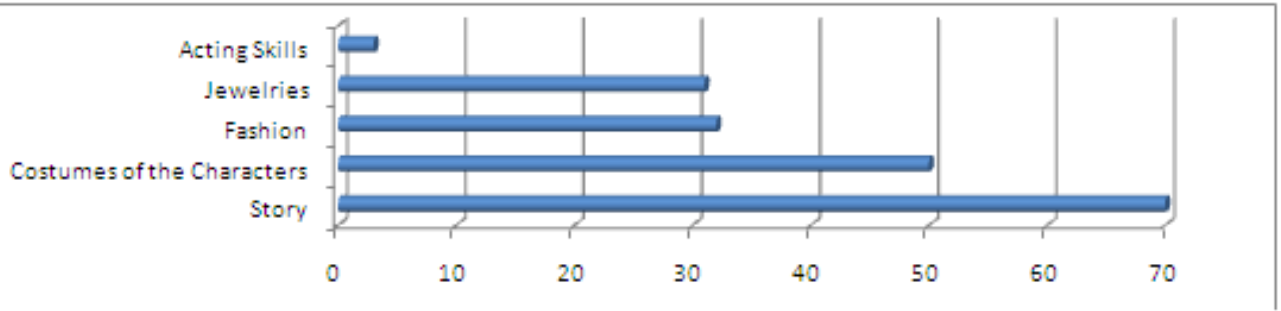

The graph shows that apart from stories viewers also show interest in actors costume, jewelries, make up, fashion etc. A play director said:

It is women's in born nature to show interest in familial matter and Indian serials use this techniques, it shows a very simple fact related to mother-in-law, sister-in-law, husband etc in a thrilling way which attracts women viewers. Moreover, sharp make-up, new hair styles, gorgeous sarees and three pieces, panjabies etc also attract them and the sources of jewelries, costumes, make-up from which parlor are shown in the scroll during the show.

\section{Impact of Indian TV serials on future generation}

Children are found spending more and more time plugged into the world of TV. In Bangladesh a large number of children are addicted to Indian TV programs especially TV serials. Children imitate the people around them, especially family members with whom they continually interact with, during the preparatory stage (Mead, 1934). If we spend all our free time in front of the TV watching Indian serials, they will be motivated to watch them. As most of the female members of our family watch Indian serials, our children are attracted to them. A nine years old respondent said- "My grandmother and mother love watching serials on Indian channels. I watch it with them".

By imitating the elder members the children experience an inappropriate socialization process which will have a negative impact on their mind. As a psychiatrist said-

The themes of most Indian TV serials are hypocrisy, lies, conspiracy, extra marital relationship etc. Children can not make difference between right and wrong as the adult can. In addition, the family dynamics shown in these shows are quite abnormal; children often begin to believe that real life is an imitation of the TV and vice-versa.

Among 45 respondents of 02 to 10 years old $78 \%$ watch Hindi serials and $22 \%$ does not watch them. Data are shown in the graph bellow-

Graph-7: The tendencies of watching Hindi serials among the respondents of 02-10 years old

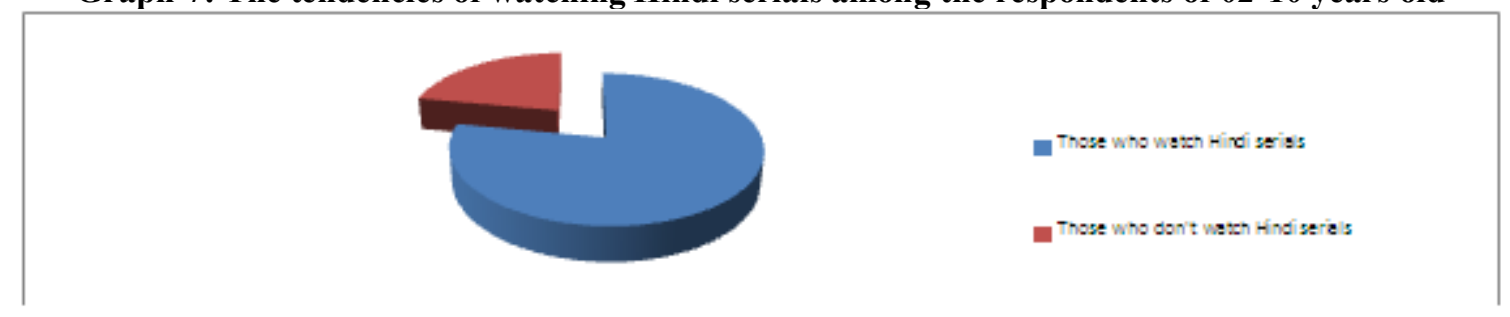

Children are constantly searching for role models whom they can follow. They won't hesitate to imitate the behavior that they see on screen. Even a character of a favorite serial may be their 'significant others' (Mead, 1964b). Mead uses the term to refer to those individuals who are most important in the development of one's self (Schaefer, 2007). For a child, especially for a female child, a favorite character portrayed in an Indian serial as most of the serials are women centric can be her role model.

\section{Case Study-03}

Name: Simu, age: 6 old, Profession: student lives in Dhaka. She says that when she grows up, she wants to be a dedicated homemaker like 'Gopi' (leading character) in 'Saath Nibhana Sathiya', aired on Star Plus because Gopi is a self-sacrificing character, ideal daughter-in-law. Moreover, she likes the character for her defenseless, forever apologizing to her family members even when they mistreat her.

Most of the serials portray the leading female characters as subordinate, passive and weak. They are far from the strong, educated, independent and honored female role models as we want for daughter to be. Moreover, by watching serials they learn to accept the stereo-types represented on the screen.

Most of the parents confess that Indian TV serials influence their children. 
Graph-8: Influence of Indian TV serials on the future generation according to parent's perception

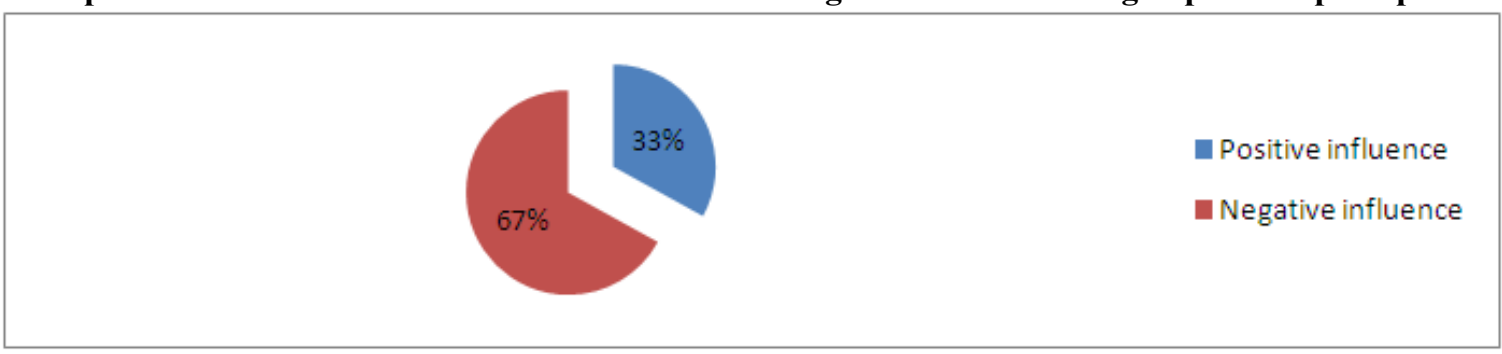

According to parent's perception, the positive impacts are: a). Children learn about Indian culture and Indian life style b). They learn about politeness and social behavior c). They accept the qualities of the characters d). Serials are helpful for children's intellectual development etc. On the other hand, the negative impacts are: a). Serials are harmful for children's academic career b). It brings changes in children's norms, values and attitudes c). Children's are attracted to Indian fashions and clothing rather the native products $d$ ). They often make quarrels and lies to create family conflict like serials e). They introduced with various illegal and immoral activities f). They often use Hindi to communicate with others instead of mother tongue which embarrasses elder members of the family g). They learn Hindi culture and develop prejudice against the indigenous culture.

\section{Respondents response to the Bangladeshi Channels}

The second part of the questionnaire of the study is related to Bangladeshi channels whether the respondents watch native channels or not. In response to this question a large number of respondents answered that they are no longer interested in watching Bangladeshi channels because of the poor quality of the programs.

Graph 9: Showing the watching pattern of Bangladeshi channels

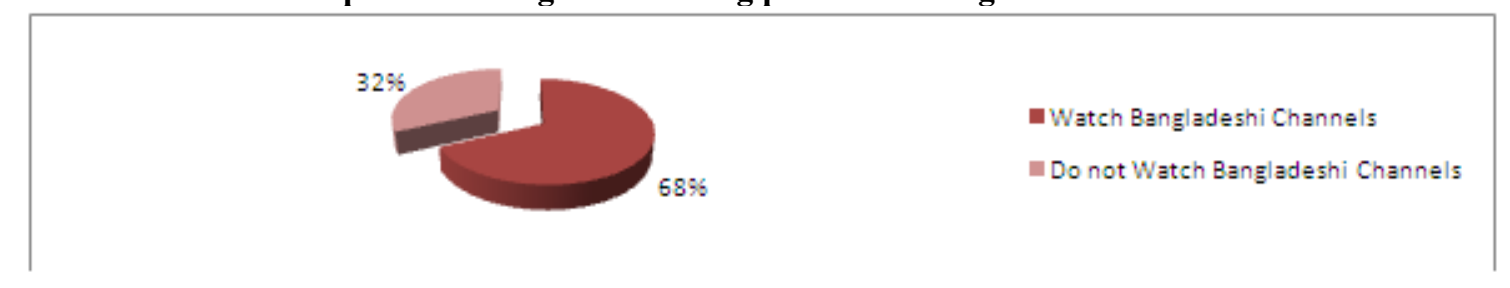

Those who watches Bangladeshi channels, most of them watch news, reality shows, musical programs etc. Those who watches or those who don't, both of them claim that the programs of our channels have failed to catch viewers because of their low quality. On the contrary, Indian channels present their programs so gorgeously that naturally millions of viewers across India stay glued to their sets to enjoy them. A play director identifies three weak points of our channels. These are:

First of all, we can not portray or speak our stories attractively; as a result viewers find no interest in watching the next episode of the serials. Secondly, we have no modern technologies to use as India has. Moreover, economic support is not enough. Thirdly, lack of 'We feelings' and likings towards native medium of arts is another reason of reluctance to watch native channels. followings

The respondents give a number of recommendations for enriching our own channels. These are the

\section{Graph 10: Respondents recommendations to improve the quality of Bangladeshi channels:}

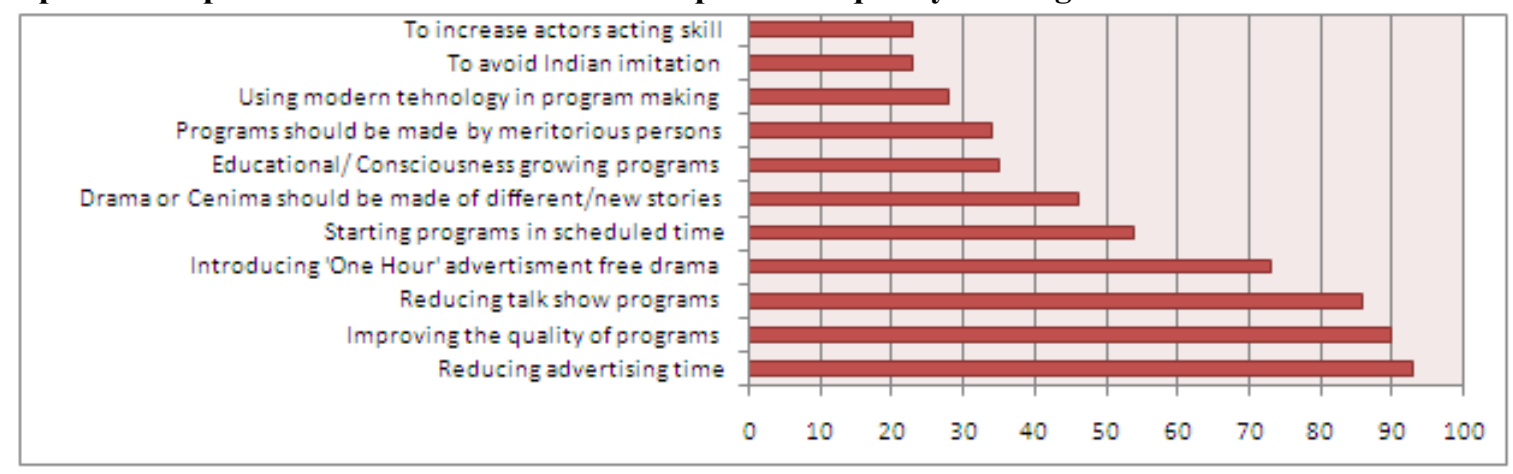




\section{Analysis And Theoretical Debate \\ Indian TV serials: Making of little Cultural/ Media Imperialism?}

Nowadays we have 23 Bangladeshi channels but not a single channel is aired in India. On the contrary, more than 90 Indian channels are aired 24 hours in our country (The STAR, 2011). Isn't it an example of media imperialism?

Moreover, a large number of Indian channels show unlimited serials and millions of viewers of our country watch these. We imitate the cultural events of the serials, the dress up, hair style, fashion of the characters and every year in every occasion of our country our markets are overflowed with the dress named after the characters. Isn't it an example of cultural imperialism?

To identify the present situation of Indian TV serials in Bangladesh we analyzed both the modernization and the dependency theories. According to modernization paradigm

"The world is becoming a single world through a satellite based communication network, which contributes in changing the viewer's notion of belongingness and their sense of common experience by producing the divers as well as pluralistic images and languages" (Brown, 2003; Pieterse, 1995 cited by Huda, 2).

On the other hand, the dependency thinkers expressed their opinion by the way that for centuries, imperialist countries imposed their cultural values on other nations. Today, as a global economic and political power, the developed countries are inevitably interfering with the cultures of other countries.

Critical theorists have coined various phrases in reference to the notions of cultural imperialism such as 'media imperialism' (Boyd- Barrett, 1977); ' structural imperialism' (Galtung, 1979); 'cultural dependency and domination' (Link, 1984); ' Cultural synchronization' (Hamelink, 1983); ' electronic colonialism (McPhail, 1987); ' communication imperialism (Sui-Nam Lee, 1988); ideological imperialism and ' economic imperialism' (Mattleart, 1994). All concepts imply that the peripheral countries are influenced by the central one.

To analyze the dependency theory authors take into account the view of David Page and William Crawley. In their book titled 'Satellites over South Asia: Broadcasting, Culture and the Public Interest' they analyzed the impact of satellite revolution in the five main countries of the South Asia - India, Pakistan, Bangladesh, Nepal and Sri Lanka.

In chapter 7 entitled 'The South Asian Footprint' Page and Crawley identified the anxieties that the popularity of Hindi channels provokes in Indian neighbors. For example, A Bangladeshi professional fears,

Hindi cable culture will become our culture. (Page \& Crawley, 226).

A Bangladeshi university student reports,

In marriage ceremonies, traditional songs are disappearing and are being replaced by Hindi movie songs. (Page $\&$ Crawley, 226).

In Nepal a student said,

The growing popularity of Hindi satellite channels is seen as undermining the role of Nepali as the national language (Page \& Crawley, 231).

So Page and Crawley identified the concept of 'imperialism' in the contemporary South Asian media environment. They viewed that Hindi popular culture almost represents South Asian popular culture. They termed it as 'Hindigenization' or ' Indianizing'.

Moreover, the tendency to imitate Indian media products can be expressed by the term ' media hybridity' (Straubharrr, 2005) which means the mixing of two or more media and they can be local and global. In Bangladesh perspective a common example may be the Talent Hunt (Singer, Dancer etc.) of different channels. It can be presented by the following way: American Idol $\rightarrow$ Indian Idol $\rightarrow$ Bangladeshi Idol. Not only the periphery countries copied the name of the program but also copied the logo and design of the programs name.

The beginnings of telecasting Bangladeshi serials which are made by imitating Indian serials (i.e. Gulshan Avenue) are another example of media hybridity. Media hybridity creates cultural hybridity, a process of interaction between centre and periphery, or in between peripheries. Kraidy defines:

Hybridity as it involves the fusion of two hitherto relatively distinct forms, styles or identities, cross cultural contract, which often occurs across the national borders as well as across cultural boundaries (Kraidy, 2005 cited by Mahmud, 9).

\section{Conclusion}

Nowadays, in our country television entertainment is all about Indian channels and most popular programs are inevitably Indian serials. At present our day to day activities show the reflection of Indian serials. Our media is changing and already starts telecasting a number of mega serials which are made by imitating Indian serials. Our social institutions like family, marriage, economy, education etc, our norms, values, socialization, social interaction all are changing. In future, we will find this changing pattern so acutely which is alarming for us. 


\section{References}

[1]. Anwar, Bushra Sameeha (2005) Hindi Serials, The Daily Star Home, The Daily Star. Bangladesh.

[2]. Ghale Neeru and Karna Rosy, (2009) Hindi Daily Soap Rocks the Fashion World,A Term paper, Date of submission- January 8, 2009 Submitted to - Miss Amy Lam, Lund University, Sweden,

[3]. Huda Zeenat (2007) Emergence of Satellite Television and Enigmatic Geo-Political Strategy of Bangladesh Government, Bangladesh e-Journal of Sociology, Volume 4, No.1.

[4]. Wikipedia (2013) Soap Opera, http://en.wikipedia.org/wiki/Soap_opera; 15 August, 2013.

[5]. Munshi Shoma, (2008) Television Soaps Play a Role in Empowering Women, http://www.deccanherald.com/content/37364/televisionsoaps-play-role-empowering.html

[6]. Wikipedia (2013) Indian Soap Opera, http://en.wikipedia.org/wiki/Indian_soap_opera; 15 August, 2013.

[7]. The STAR, A weekly publication of the Daily Star, 6 August 2010, Volume 9, Issue 32.

[8]. Khan, Tamanna (2011) Where the Sky is Limited. The STAR, A weekly publication of the Daily Star, 16 September, 2011, Volume 10, Issue 35, Mundus Masters in Journalism and Media within Globalization: The European Perspective, Department of Information and Media Studies, Aarhus University, Denmark, smahmud.weebly.com/uploads/4/.../globalization_culture_media.pdf

[9]. Mead, George H. (1934). Mind, Self and Society.edited by Charles W. Morris, Chicago.University of Chicago Press.

[10]. Mead, George H. (1964b) The Genesis of the Self and Social Control. Pp. 267-293 in Selected Writings: George Herbert Mead. edited by Andrew j. Reck. Indianapolis. Bobbs-Merrill.

[11]. Page Devid and Crawley William (2001), Satellites over South Asia: Broadcasting, culture and the Public Interest, Sage publication,India.

[12]. Shameem, Mahmud (2009) Globalization and Cultural hybridity in the Context of New Digital Media, Exam paper of Erasmus

[13]. Schaefer, Richard T. (2007). Sociology. New York. McGraw-Hill. 